\title{
Evaluation of Telecommunication Companies Using Data Envelopment Analysis: Toward Efficiency of Mobile Telephone Operator in Tanzania
}

\author{
Munir Said Suleiman*, Nitham Salum Hemed, Jiuchang Wei \\ School of Management, University of Science and Technology of China, Hefei, Anhui 230026, P.R. China. \\ * Corresponding author. Email: massak@mail.ustc.edu.cn \\ Manuscript submitted December 12, 2017; accepted February 6, 2018. \\ doi: 10.17706/ijeeee.2018.8.3.154-164
}

\begin{abstract}
The mobile telephone sector has shown dramatic growth in Africa. With the number of mobile phone operators raised, now Tanzania considered the largest telecommunications network in East Africa with over 40 million registered subscribers and mobile money accounts. However, the services provided by operators have not been assessed by the Authority. Therefore, this paper focus on evaluating the efficiency of mobile phone operators in Tanzania. A data envelopment analysis (DEA), NonRadial and Oriented model on the slack-based measure (SBM) was used for the performance analysis. A five input and five output variables generated from 27 reports (2010 to 2016) of Tanzania Communications Regulatory Authority (TCRA) was used to study the efficiency of mobile phone operators. The results show only three operators are efficient with Vodacom-Tanzania ranked as first, followed by Airtel-Tanzania, and Tigo as the third. While Zanzibar Telecom (Zantel), Smart, Halotel and Tanzania Telecommunication Company Limited (TTCL) considered being inefficiency operators.
\end{abstract}

Key words: Data envelopment analysis, efficient, mobile phone, slack-based measure.

\section{Introduction}

The mobile telecommunications sector has shown remarkable growth in the last few decades, becoming one of the greatest fascinating divisions of technology diffusion in societies [1]-[5]. According to the United Nations (UN) telecommunication agency, the number of mobile users reached 5.3 billion at the end of 2010 [6]. An estimated 3.2 billion of those mobile subscribers were in developing countries [7], which is equivalent to 47 percent of the total world population in 2009. Telecommunication services recognized as a vital sector for development of a country's society and economy [7]-[9]. The services have made a noticeable improvement in permitting a large amount of information flow around the globe; reducing transaction time and costs; motivating customer demands for world-class services, products, and brands [10]; and altering lifestyles within societies [11].

Currently, mobile phones are numerous and cheap; a person can have more than one smartphone used as a platform for accessing the Internet, performing financial services, e-government services, reservation services (like a hotel, tax, and flight booking, or ordering meals), and e-health [8], [12]. For example, in Kenya, the giant mobile network operator Safaricom launched an innovative money transfer service known as M-Pesa (Mobile Money) in 2007. This technological innovation spread into neighboring country Tanzania as Tigo-Pesa operated by Tigo telecommunication company, M-Pesa operated by Vodacom-Tanzania, 
Ezy-Pesa operated by Zanzibar Telecom Limited (Zantel), and Airtel-Money operated by Airtel-Tanzania. All of those services aim to simplify money transfers without physical presence at the bank. By using mobile money [13] through the mobile phone, people can perform money exchanges in ways that are considerably faster, cheaper, time-saving, and accessible than regular bank money transfer services [14]-[16].

Tanzania mobile market considered as one of greatest competitor in Africa [17]. Competition is on both mobile and fixed sub-sectors, but high competition is in mobile telephone operator. Seven major mobile operators; Airtel-Tanzania, Smart, Halotel, Tigo, Tanzania Telecommunication Company Limited (TTCL), Vodacom-Tanzania, and Zantel compete regionally or nationally. Regardless, allocation of a high number of licenses to telecom operators and great competition in the market, Tanzania scored poorly on the World Economic Forum's (WEF) and Networked Readiness Index (NRI). Categorized in worst NRI position in East Africa region [18]. Nevertheless, according to NRI, the Tanzanian Government ranked far advanced compared to the business or individual sectors. The possible reason for the fairly favorable government position is that Information Communication Technologies (ICTs) standardized as central government's vision for the future. With the creation of the National Information and Communication Technology Broadband Backbone (NICTBB) boost Tanzania to the higher ranking significantly [18]

Recently, Tanzanian mobile telephone operators have increased tremendously. However, the TCRA has neglected to assess services provided by operators. Therefore, the main objective of this paper is to evaluate the efficiency of mobile telephone operators in Tanzania, using data envelopment analysis (DEA). Several determining factors; basic prepaid per minute tariff (without tax), telecom subscriptions, registered subscriptions, mobile money subscriptions and percentage shares of traffic per operators analyzed for seven major mobile telephone operators in Tanzania. The factors above are valuable to evaluate the services of mobile telephone operators. However, in previous studies have not been well addressed.

The slacks-based measure (SBM) of DEA [19] model is adapted to check the efficiency of mobile phone operator in Tanzania based on the factors mentioned earlier. This paper has six sections; the first section is an introduction. Overviews of Tanzanian mobile telecom operators given in section two. Section three briefly explain the literature reviews, while the methodology and data collection presented in section four. The DEA results, the performance of variables, and efficient, and inefficient decision-making unit (DMU) provided in the fifth section. Conclusion and possible future directions provided in section six.

\section{Overviews of Tanzania Mobile Telecom Operators}

In recent year, Tanzanian telecommunications sector is undergoing a high process of transformation due to significant improvement of government policies. [20]. Those policies resulted in highly increased of subscribers [21]. Arose of people incomes, great competition among operators, lower tariffs rate, and market advertisement contributed to a high number of mobile subscribers [18].

The mobile telephone industry has shown dramatic growth in Africa. Tanzania as the largest telecommunications network in East Africa has seven major operators with over 40 million registered subscribers and mobile money accounts in Tanzania. There is only one public mobile and fixed network operator; TTCL with 293495 subscribers. Others are private operators; Vodacom-Tanzania has highest subscribers of 12.4 milion, followed by Tigo with 11.7 milion subscribers. Airtel-Tanzania is the third with 10.5milion subscribers. Other competitors in the market are Smart, Halotel, and Zantel (TRCA Report of Dec 2016).

However, the performance provided by mobile telephone operators in Tanzania remains an issue, and yet no significant research has been conducted to evaluate the efficiency of operators. Hence this paper attains to fill that gaps. 


\section{Literature Review}

DEA is a very popular tool among the researchers for its importance to evaluate the efficiency and performance of telecommunication sectors and other service operations. For example, Kayisire and Wei [22] used DEA tool to measure various benchmarking industries and evaluate the performance of Information and Communication Technology (ICT) adoption in Africa.

Currently, the efficiency of services provided by telecommunication sector has drawn much attention to the researchers and policymakers. In various studies [10], [20], [23] applied DEA for regulation of telecommunication utilities. In the reference [24], DEA integrated with fuzzy data envelopment analysis (FDEA), to assess the efficiency of wireless communication sectors in 42 countries with three inputs and five output. And results obtained to identify the impact of specific inputs or outputs on performance.

In the reference [25] proposed a benchmark to the wireless mobile communication service provider in the USA. The impact of merger and acquisition activities on efficiencies investigated. Lupi [26] used a simple approach to assess the internal efficiency of national regulatory authorities (NRAs) by considering outcomes on the regulation of the market. The approach proposed to enhance a person to be aware of different regulatory measures and their effectiveness. Zhu [27] used multiple inputs and outputs in DEA to evaluate the performance of telecommunication company in Korea. Azadel et al. [28] focused on assessment and rank of telecommunication industry based on International Telecommunication Union (ITU) standard.

Shin and Sohn in (2004) [29] evaluated multiple mobile telecommunication customers using DEA based on mobile subscribers. Using DEA and Principal Component Analysis (PCA), data from 27 developing and developed countries applied. A total of nine indicators were used to show the significance of the approach. The results show that profit-driven from customer efficiency score as the main target of telecommunication companies. Moreover, the results identified strong and weak points. And show most efficient output and input of each sector for further consideration in overall management.

In 2004, Facanha and Resende constructed synthetic efficiency score for local telephony in Brazil between 1998 to 2002. The flexible DEA used to obtain the efficiency scores [23]. The result suggested that price cap approach should be used together with productivity offset. Giokas and Pentzaropoulos [30] compared telecommunications efficiency of 30 members states of Organisation for Economic Co-operation and Development (OECD). Data from OECD database in 2005 implemented in Analytic Hierarchy Process (AHP) and DEA tool to evaluate the performance. The results show both productivity and revenue plane in eight countries are efficient. Lam and Shiu [31] applied DEA at the provincial level to check the efficiency of telecommunication sector in China. The results declare that efficiency of provinces on the eastern zone is relatively higher than those in western and central zones.

To the best of knowledge, our paper is the first one focus on evaluating the efficiency of telecommunication companies using data envelopment analysis, specific on mobile telephone operators in Tanzania.

\section{Methodology and Data Collection}

\subsection{Methodology}

The method used in this study selected based on the availability of data on mobile telephone sectors in Tanzania. Two approaches can be applied; A parametric approach which uses an econometric model to assess the efficiency, and a non-parametric approach which applies the mathematical method to assess the efficiency. In this study, DEA which is a non-parametric tool has been used to measure the efficiency. The efficiency score of DEA for certain decision-making units (DMUs) in a sample data set is not to an absolute standard but are considered relative by other DMUs. The best DMU in the data set used as a reference to compare with others. 
DEA is in two main form depend on different production possibility sets, and corresponding efficient one preferred. One is the Charnes, Cooper, and Rhodes (CCR) model proposed in 1978 [32] and the other is the Banker, Charnes, and Cooper (BBC) model proposed in 1984 [33]. The return to scale (RTC) is the main difference between these two models. The CCR uses the constant return to scale (CRC), while the BCC uses variable return to scale (VRT) surface. Both models can be either in oriented or non-oriented scenarios for input and output. The appropriate model applied in our study (with seven DMUs of mobile telephone operators) is CRT, non-radial, oriented model on the slack-based measure (SBM) to evaluate the efficiency of mobile telephone operators in Tanzania. The efficiency score of DMUs can be expressed as the sum of outputs over the sum of inputs as shown below:

$$
\text { Efficiency score, } E S=\sum_{p=1}^{q} y_{p j} / \sum_{r=1}^{s} x_{r j}, \quad \text { while } \quad \sum_{p=1}^{q} y_{p j} / \sum_{r=1}^{s} x_{r j} \leq 1
$$

For all $j=1,2, \ldots, n ; r=1,2, \ldots, s$ and $p=1,2, \ldots ., q ; \quad y_{p j}$ is the output $p$ produced by $D M U_{j} ; \quad x_{r j}$ is the input r used by $D M U_{j}$.

Furthermore, The Super-SBM oriented model (introduced later) used to rank the efficient DMUs based on the super-SBM efficiency score. The score can be greater than one, a contrast from SBM efficiency score with highest score one.

\subsubsection{Definition of efficient and inefficient SBM}

The DEA Oriented, NonRadial SBM efficient methodology applied in this work to measure the relative efficiency of DMUs (Tanzanian mobile telephone operators). The non-radial SBM efficient considered because, it has a direct influence on the non-radial input and output slacks in calculate the efficiency score (Tone, 1999). In that respect, the non-radial concept is significant in evaluating efficiency by measure output shortfall and input excess.

The SBM scheme for number (n) of DMUs expressed as matrices $X=\left(x_{i j}\right) \in i^{u \times v}$ for input and $Y=\left(y_{i j}\right) \in \mathrm{i}^{w \times v}$ for output, with the positive dataset, $X>0$ and $Y>0$. While the production possibility set expressed as $P P=\{(x, y) \mid x \geq X \lambda, y \leq Y \lambda, \lambda \geq 0\}$, whereby $\lambda$ is a non-negative vector in $\mathrm{i}^{v}$. When no output shortfalls and no input excesses, means DMU is SBM efficient with efficiency score; $\theta^{*}=1$, $s^{+*}=0$ and $s^{-*}=0$ existed in any optimal solution. When DMU is weak, the SBM efficient score, $\theta^{*}=1$ and $s^{+*} \neq 0$ or/and $s^{-*} \neq 0$ for several $i$ and $j$.

For SBM inefficient $\operatorname{DMU}\left(x_{0}, y_{0}\right)$, we express, $x_{0}=X \lambda^{*}+s^{-*}$, for input and $y_{0}=Y \lambda^{*}-s^{+*}$, for output. If input excess eliminated and output shortfall augmented, the SBM projection to $\operatorname{DMU}\left(x_{0}, y_{0}\right)$, can be used to improve it or make it efficient, as expressed in $x_{0} \leftarrow x_{0}-s^{-*}, y_{0} \leftarrow y_{0}+s^{+*}$, for input and output respectively. And the reference set to $\left(x_{0}, y_{0}\right)$, corresponding to positive $\lambda_{j}^{*} s$. In a condition of multiple optimal solutions, the reference set is not unique; therefore, the scenario of multi-choices for a specific purpose existed. The reference set $R_{0}$ defined as $R_{0}=\left\{j \mid \lambda_{j}^{*}>0\right\}$ with $(j \in\{1, \ldots, n\})$. By using $R_{0}$; we can represent $\left(x_{0}, y_{0}\right)$, as $x_{0}=\sum_{j \in R_{0}} x_{j} \lambda_{j}^{*}+s^{-*}$ and $y_{0}=\sum_{j \in R_{0}} y_{j} \lambda_{j}^{*}-s^{+*}$. The $\left(x_{0}, y_{0}\right)$, expression is a certain point on the frontier efficiency, expressed as a member of the reference set. The $R_{0}$ 
of positive combination produce efficient member [22].

The Oriented, NonRadial SBM process gives the efficient score ranges between 0 and 1 . If DMU is the benchmark of the PP with no input or output slacks, then it provides the unit value. Since it is possible for best DMU to have unit value, therefore, a Super SBM efficient [34] applied to distinguish SBM efficient with unit value.

\subsubsection{Definition of super SBM efficient}

The Super SBM model derived from SBM efficient model to rank the DMUs with unit value. (described in the previous sub-section). Assume $D M U_{0}=\left(x_{0}, y_{0}\right)$ is SBM efficient, i.e., obey the condition of $\theta^{*}=1$, $s^{+*}=0$ and $s^{-*}=0$. In that respect, it suggested using super efficiency score, $\vartheta^{*}$ of Super SBM model to rank DMUs. [34].

Super-efficiency $\quad$ expressed $\quad$ as: $\quad \vartheta^{*}=\min \vartheta=\frac{1}{u} \sum_{i=1}^{u} \bar{x}_{i} / x_{i 0} / \frac{1}{w} \sum_{r=1}^{w} \bar{y}_{r} / y_{r 0}, \quad$ subjected $\quad$ to $\bar{x} \geq \sum_{j=1, j \neq 0}^{v} x_{i j} \lambda_{j}, i=1, \ldots ., u, \quad \quad \quad \quad \quad \quad \quad \leq \sum_{j=1, j \neq 0}^{v} y_{r j} \lambda_{j}, r=1, \ldots ., w, \quad$ while $\lambda_{j} \geq 0, j=1, \ldots, v, j \neq 0 ; \bar{x} \geq x_{0}$, and $\overline{\mathrm{y}} \leq \mathrm{y}_{0}$.

\subsubsection{Data collection}

The model used related to the work on the reference [31], that mobile phone subscribers and fixed-line used as output variables to measure the efficiency and productivity. There is no specific way to decide the output variables in the telecommunication industry. Previous research used the total number of subscribers, the number of the call made in a minute or number of access lines as outputs while others considered total revenue as the output variable. However, focus on total revenue to decide output variable [31] claimed that, variations in the value of services and a greater number of connected subscribers could replicate in telecommunications charges.

Data utilized in this paper collected from 27 TCRA reports (TCRA Statistics Reports from 2010 to 2016) and used to measure the efficiency of major mobile telephone operators in Tanzania. A total of seven DMUs considered with each operator as DMU. The analysis conducted using five inputs variables. The Average Voice Total Local Tariffs (AVTLT) (On-Off-Net Tariff); Average Voice East Africa Tariffs (AVEAT); Average Voice International Tariffs (AVIT); Average Local SMS Tariffs (ALST); Average International SMS Tariffs (AIST); On another hand same number of variables used as outputs named Average Subscription Market Share (ASMS); Average Registered Subscriptions (ARS); Average Total Local Net Traffic Shares (ALNTS); Average Internationals Traffic Shares (AITS); and Average Mobile Money Subscriptions Market Share (AMMS).

Table 1. The Average Input and Output Variables

\begin{tabular}{|c|c|c|c|c|c|c|c|c|c|c|}
\hline $\begin{array}{c}\text { Operator } \\
\text { (DMU) }\end{array}$ & $\begin{array}{c}\text { (I) } \\
\text { AVTLT }\end{array}$ & $\begin{array}{c}\text { (I) } \\
\text { AVEAT }\end{array}$ & $\begin{array}{c}\text { (I) } \\
\text { AVIT }\end{array}$ & $\begin{array}{c}\text { ALST } \\
\text { AVS }\end{array}$ & $\begin{array}{c}\text { AIST } \\
\text { AISMS }\end{array}$ & $\begin{array}{c}\text { (0) } \\
\text { ARS }\end{array}$ & $\begin{array}{c}\text { (O) } \\
\text { ALNTS }\end{array}$ & $\begin{array}{c}\text { (O) } \\
\text { AITS }\end{array}$ & $\begin{array}{c}\text { (0) } \\
\text { AMMS }\end{array}$ \\
\hline Airtel Tanzania & 233 & 482 & 874 & 67 & 127 & 29.2 & 94.6 & 31.46 & 35 & 23.67 \\
\hline Smart & 103 & 329 & 1203 & 33 & 88 & 0.8 & 81.7 & 0.04 & 1 & 0.001 \\
\hline Halotel & 228 & 552 & 1330 & 30 & 95 & 6 & 82.8 & 6.7 & 6.3 & 0.001 \\
\hline Tigo & 251 & 486 & 980 & 54 & 109 & 24.7 & 99.2 & 29.31 & 21.8 & 32.67 \\
\hline TTCL & 187 & 347 & 490 & 47 & 103 & 1 & 100.9 & 1.749 & 2.7 & 0.001 \\
\hline Vodacom Tanzania & 231 & 491 & 741 & 50 & 114 & 37.3 & 98.1 & 32.4 & 30.3 & 41.83 \\
\hline Zantel & 165 & 384 & 639 & 51 & 101 & 6.3 & 86.9 & 3.77 & 8.9 & 1.833 \\
\hline
\end{tabular}


Data presented in Table 1, used to measure efficiency and super efficiency score of DMUs. All DMUs was operated on the mobile network except, TTCL and Zantel operated on both fixed and mobile network. Some of those companies covered a large area of Tanzania, for example, Airtel-Tanzania, and Vodacom-Tanzania while others like; Smart, Halotel, and Zantel are very popular in major cities. Moreover, Airtel-Tanzania is the only company allows subscribers to access the network with the same local rate while in East Africa regions. The cost rate in Table 1, are subjected without tax.

\subsection{DEA Results}

The statistical results in Table 2, obtained using DEA-SOLVER Pro 8.0 software run under oriented SBM with a constant return to scale (CRS). The DEA used to measure the efficiency of Tanzanian mobile telephone operators using output oriented models which expand the output, but inputs remain unchanged to produce best-practice frontier [35].

Table 2. Operators with SBM and Super SBM Score

\begin{tabular}{|l|l|l|l|}
\hline Operator (DMU) & SBM score & Super SBM Score & Rank \\
\hline Vodacom Tanzania & 1 & 1.439238 & 1 \\
\hline Airtel Tanzania & 1 & 1.030961 & 2 \\
\hline Tigo & 1 & 1.011012 & 3 \\
\hline Zantel & 0.4133 & & 4 \\
\hline Smart & 0.0003 & & 5 \\
\hline Halotel & 0.0002 & & 6 \\
\hline TTCL & 0.0002 & & 6 \\
\hline
\end{tabular}

Most efficient operators considered as reference points for other operators and expressed the best-practice frontier. Subsequently, for less efficiency or inefficient operator needed to be projected to the best frontier by referring to one or many efficient operators (DMUs) as a relative reference set (lambda) to achieve the efficiency frontier.

Efficient operators regarded as the reference set. With the group of efficient operators on the frontier offer a projection to less efficiency or inefficient operators on the frontier by efficient value, which is a vector of efficient prolific operators (Vincova', 2005).

Three DMUs ranked as efficiency operators while other four company considered as inefficiency. Regarding that, further analysis needed to distinguish efficiency operators with unit value. Hence the NonRadial Oriented Super-SBM-C, based on CRS were used to justify the super efficiency DMUs.

The Airtel-Tanzania, Tigo, and Vodacom-Tanzania reflected a projection of inputs/outputs using their reference set in the frontier which is equal to 1 . The Smart and Halotel both reflected Vodacom-Tanzania $=$ 0.446 and 0.6 in the Frontier respectively. Moreover, the TTCL projected to Vodacom-Tanzania $=0.661$ in the frontier, while Zantel applies Smart $=0.184$, TTCL $=0.459$, and Vodacom-Tanzania $=0.261$ to produce best practice frontier.

\subsection{Performance Variables}

In this study, the total of five inputs and five outputs variables of the mobile telephone operators in Tanzania have been evaluated. The DEA provides the performance of each variable which subjected to negative changes, neutral (unchanged) or positive changes.

\subsubsection{Performance of inputs variables}

Refer to the Fig. 1, only neutral and negative changes occurred in the input variables. Starting with AVTLT, negative changes appeared only on Halotel and TTCL while other operators remain unchanged. For AVEAT and AIST variables, all three efficient DMUs unchanged while the rest subjected to negative changes. In AVIT 
variable, negative changes only occurred on Smart and Halotel with others remain unchanged. Moreover, in ALST variable negative changes appeared on Smart, TTCL and Zantel with another operator remain neutral.

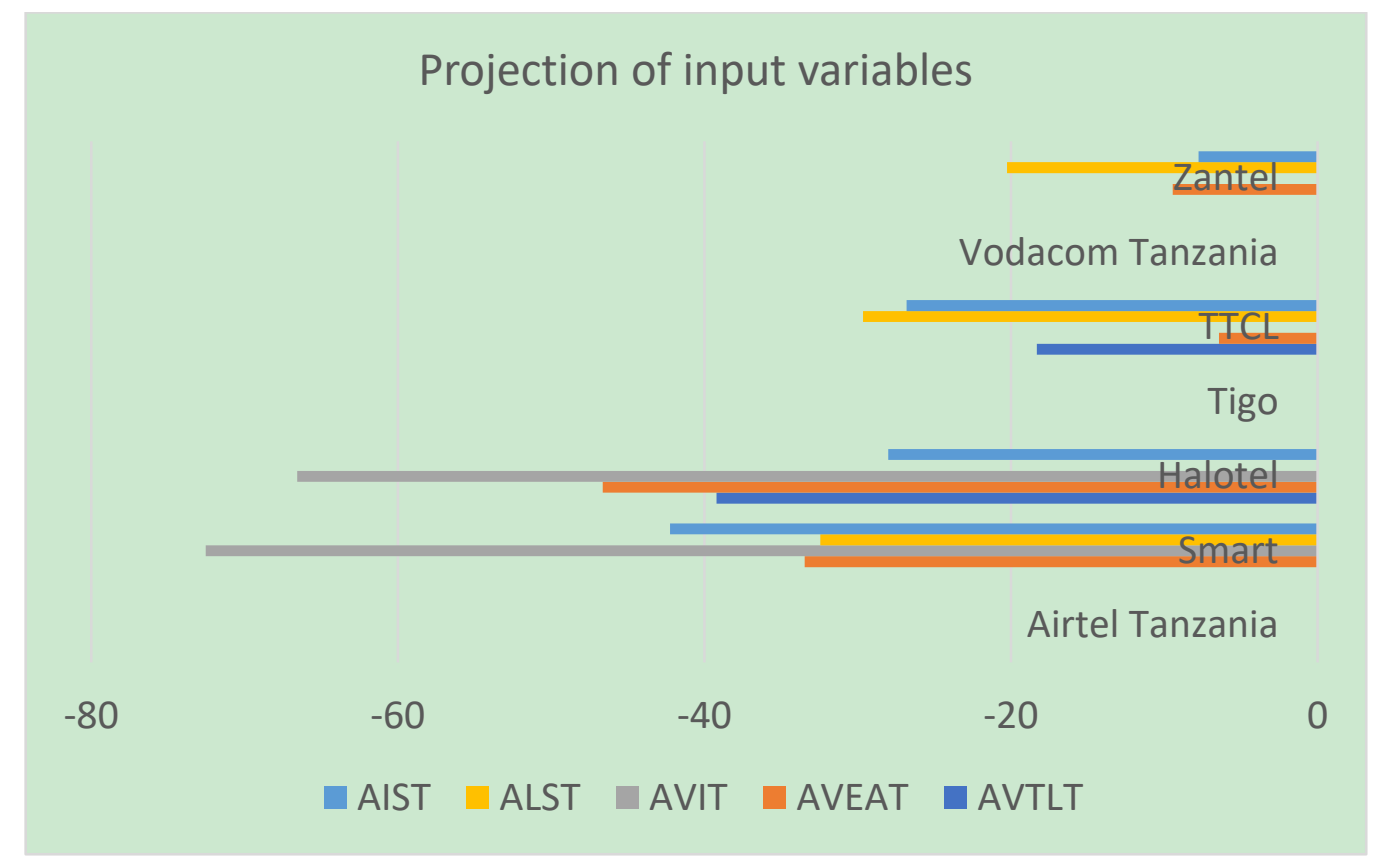

Fig. 1. Projection of input variables.

\subsubsection{Performance of output variables}

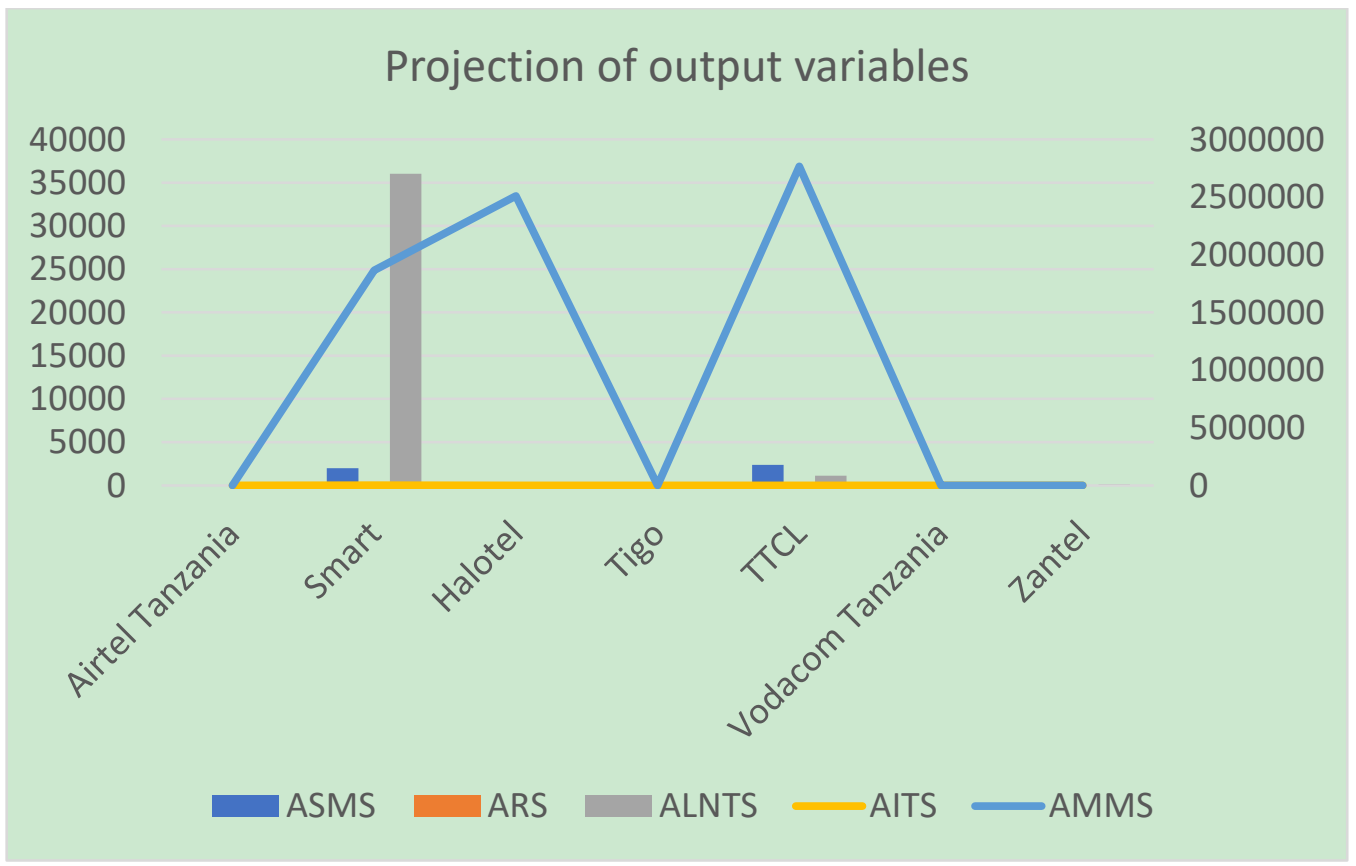

Fig. 2. Projection of output variables.

For the performance of output variables, starting with ARS, all operators remain unchanged. On another hand in ASMS, AITS, AMMS and ALNTS variables, only positive changes occurred on all inefficient operators while efficient operator remains neutral. Also, high changes noticed on inefficient operators especial for Smart, Halotel, and TTCL.

\subsubsection{Efficient and inefficient DMU}

The efficiency and inefficiency DMUs obtained from the results of SBM-C model in Table 2. The results 
show three out of seven operators are efficient with the total average efficiency score 0.4877 , and standard deviation of 0.501 . The values obtained indicated that performance of operators for inputs/outputs variables needed to be improved by $51.23 \%$.

Super-SBM-C model used to differentiate the efficient operators with unit value. The results ranked Vodacom-Tanzania as the most efficient operator with a score of 1.43924, followed by Airtel-Tanzania with a score of 1.03096, and the third is Tigo with a score of 1.01101 .

On another hand, four operators were inefficient with the sum of their score less than 0.5. The low SBM score especially noticed on the Halotel, TTCL, and Smart (see Table 2).

\section{Conclusion and Discussions}

In concluding this study, the DEA SBM-C model has been used to evaluate the efficiency of services provided by seven major mobile telephone operators in Tanzania using some inputs/outputs variables from TCRA reports (TCRA Statistics Reports from 2010 to 2016).

The results indicate three operators as efficient and four as inefficient DMUs. Furthermore, the result expanded using Super-SBM-C model to check super efficiency among efficient operators. This model ranked Vodacom-Tanzania as first, followed by Airtel-Tanzania, and Tigo as the third.

The Vodacom-Tanzania (founded in 1999), Airtel-Tanzania and Tigo operators are old operators, provide numerous service and well known in the Mobile Market of Tanzania [18], not surprising to perform better among others, with the average voice Telecom subscriptions of over 12, 10, 11 million respectively [36] (TCRA 2016 Quarterly Statistics Reports Dec 2016).

Surprisingly to Halotel operator, a new company launched in October 2015 in Tanzania provides cheap input (ALST and AIST) services, Firth in ASMS output took the last position in the SBM-score. For TTCL, input services provided are relatively cheap (refer to Table 1). However, it performs poorly on SBM score.

On the other hand, Smart operator does not perform well because many of outputs services (ASMS, ARS, ALNTS, AITS, and AMMS) are either in a relatively low rate or not provided at all. The same factors applied in Zantel, however, input services are competitive with other operators.

In future research, we would like to check the possibility to include revenue and profit of each operator as the factor to evaluate efficiency. Additionally, the coverage area, number of employees with total assets each operator owned may be included to have more realistic meaningful. Furthermore, this work may expand to compare the efficiency of mobile operators of developing nations with, the developed one.

\section{Acknowledgements}

I would like to thank you, Prof. Murray Sherk, for editing, proofreading, and suggesting to improve this article.

\section{References}

[1] Tiarawut, S. (2013). Mobile technology: Opportunity for entrepreneurship. Wireless Personal Communications, 69(3), 1025-1031.

[2] Saxena, V., et al. (2009). Efficiency analysis and benchmarking of telecommunication sector In India. Proceedings of the 2009 First International Conference on Computational Intelligence, Modelling and Simulation. CSSim 2009 Information Getting Started (pp. 270-5).

[3] Liu, C.-J., et al. (2009). The public incumbent's defeat in mobile competition: Implications for the sequencing of telecommunications reform. Telecommunications Policy, 33(5-6), 272-284.

[4] Gupta, R., \& Jain, K. (2015). Adoption behavior of rural India for mobile telephony: A multigroup study. Telecommunications Policy, 39(8), 691-704. 
[5] Glotz, P., Bertschi, S., \& Locke, C. (2006). Introduction: mobile phones and mass communications. Knowledge Technology \& Policy, 19(2), 3-6.

[6] Tsivor, K. K. (2011). Renewable energy (green ICT) support for mobile communications in Africa. Proceedings of 2011 33rd International Telecommunications Energy Conference (p. 6).

[7] Kaba, B., et al. (2009). Micro factors influencing the attitudes toward and the use of a mobile technology: A model of cell-phone use in Guinea. IEEE Transactions on Professional Communication, 52(3), 272-290.

[8] Kumar, P., Paton, C., \& Kirigia, D. (2016). I've got 99 problems but a phone ain't one: Electronic and mobile health in low and middle income countries. Archives of Disease in Childhood, 101(10), 974.

[9] Chircu, A. M., \& Mahajan, V. (2009). Perspective: Revisiting the digital divide: An analysis of mobile technology depth and service breadth in the BRIC countries. Journal of Product Innovation Management, 26(4), 455-466.

[10] Ramachander, S. (2016). The price sensitivity of mobile use among low income households in six countries of Asia. Telecommunications Policy, 40(7), 673-691.

[11] Debnath, R. M., \& Shankar, R. (2008). Benchmarking telecommunication service in India. An application of data envelopment analysis. Benchmarking: An International Journal, 15(5), 584-98.

[12] Lesitaokana, W. 0. (2014). Key issues in the development of mobile telephony in Botswana (1998-2011): An empirical investigation. New Media \& Society, 16(5), 840-855.

[13] Eetharam, B., \& Johnson, D. (2015). Mobile money's impact on Tanzanian agriculture. IEEE Software, 32(1), 29-34.

[14] Vizzarri, A., \& Vatalaro, F. (2014). m-Payment systems: Technologies and business models. Proceedings of 2014 Euro Med Telco Conference (p. 6).

[15] Namisiko, P., Sakataka, W., \& Wanyama, S. M. (2014). Influence of mobile operating system characteristics on adoption of mobile devices in education: The case of higher learning institutions in Kenya. International Journal of Computer and Information Technology, 3(6), 1496-503.

[16] Sabokwigina, D., et al. (2013). SMS advertising in Tanzania: Factors affecting consumer attitudes. 2013 Ist-Africa Conference and Exhibition (Ist-Africa).

[17] Mekonnen, D. K., et al. (2015). Innovation systems and technical efficiency in developing-country agriculture. Agricultural Economics, 46(5), 689-702.

[18] Esselaar, S., \& Adam, L. (2013). Understanding what is happening in ICT in Tanzania: A supply- and demand-side analysis of the ICT sector. Evidence for ICT Policy Action.

[19] Chang, Y.-T., et al. (2013). Environmental efficiency analysis of transportation system in China: A non-radial DEA approach. Energy Policy, 58, 277-283.

[20] Gorp, A., \& Maitland, C. (2009). Regulatory innovations in Tanzania: The role of administrative capabilities and regulatory governance. Info, 11(1), 64-77.

[21] Samanta, S. K., et al. (2009). Tariff balancing for increased subscription and revenue in a mobile network. International Journal of Mobile Communications, 7(2), 213-231.

[22] Kayisire, D., \& Wei, J. (2016). ICT adoption and usage in Africa: Towards an efficiency assessment. Information Technology for Development, 22(4), 630-653.

[23] Facanha, L. O., \& Resende, M. (2004). Price cap regulation, incentives and quality: The case of Brazilian telecommunications. International Journal of Production Economics, 92(2), 133-144.

[24] Azadeh, A., et al. (2011). An integrated fuzzy DEA algorithm for efficiency assessment and optimization of wireless communication sectors with ambiguous data. International Journal of Advanced Manufacturing Technology, 52(5-8), 805-819.

[25] He-Boong, K., Stoeberl, P. A., \& Seong-Jong, J. (2008). Measuring comparative efficiencies and merger 
impacts of wireless communication companies. Benchmarking: An International Journal, 15(3), 212-24.

[26] Lupi, P., et al. (2011). On the assessment of regulators' efficiency: an application to European telecommunications. Info, 13(1), 61-73.

[27] Zhu, J. (2003). Efficiency evaluation with strong ordinal input and output measures. European Journal of Operational Research, 146(3), 477-485.

[28] Azadeh, M. A., Bukhari, A., \& Izadbakhsh, H. (2006). Total assessment and optimization of telecommunication sectors by multivariate approach. Proceedings of 2006 4th IEEE International Conference on Industrial Informatics (pp. 659-63).

[29] Shin, H. W., \& Sohn, S. Y. (2004). Multi-attribute scoring method for mobile telecommunication subscribers. Expert Systems with Applications, 26(3), 363-368.

[30] Giokas, D. I., \& Pentzaropoulos, G. C. (2008). Efficiency ranking of the OECD member states in the area of telecommunications: A composite AHP/DEA study. Telecommunications Policy, 32(9-10), 672-685.

[31] Lam, P.-L., \& Shiu, A. (2008). Productivity analysis of the telecommunications sector in China. Telecommunications Policy, 32(8), 559-571.

[32] Charnes, A., Cooper, W. W., \& Rhodes, E. (1978). Measuring the efficiency of decision making units. European Journal of Operational Research, 2(6), 429-44.

[33] Banker, R. D., Charnes, A., \& Cooper, W. W. (1984). Some models for estimating technical and scale inefficiencies in data envelopment analysis. Management Science, 30(9), 1078-1092.

[34] Tone, K. (2002). A slacks-based measure of super-efficiency in data envelopment analysis. European Journal of Operational Research, 143(1), 32-41.

[35] Cook, W. D., Tone, K., \& Zhu, J. (2014). Data envelopment analysis: Prior to choosing a model. Omega-International Journal of Management Science, 44, 1-4.

[36] TCRA 2016 Quarterly Statistics Reports. (2017). Retrieved from the website: https://www.tcra.go.tz/publication-and-statistics/statistics

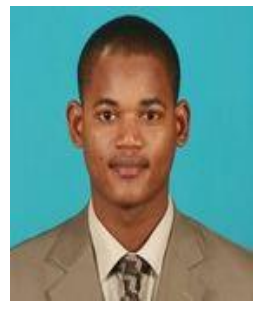

Munir Said Suleiman is a Ph.D candidate at the Department of Management Science and Engineering in School of Management at University of Science and Technology of China. His research interest including management information system, data envelopment analysis, forecasting methods, information communication technology, computer networking, cloud computing and big data. He served as a reviewer of Computer Networks, Computer Networks Journal and Optical Fiber Technology.

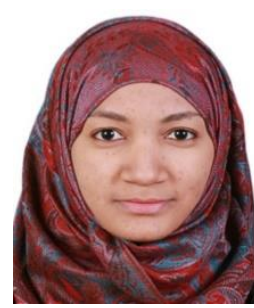

Nitham Salum Hemed received her master degree in business administration from School of Management at University of Science and Technology of China. Her research interest is in the area of marketing strategic, entrepreneurship, procurement, supplies chain management, data envelopment analysis, and management information system.

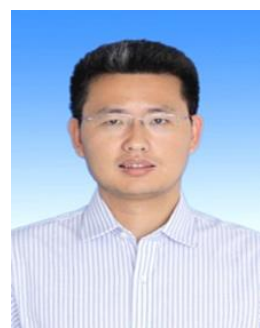

Jiuchang Wei is professor of School of Management at University of Science and Technology of China. He is also a visiting scholar at Hazard Reduction and Recovery Center, Texas A\&M University, Curtin University Sustainability Policy Institute, and the Curtin University of Technology. He received his Ph.D. in management science and engineer from University of Science and Technology of China. His primary research interests are disaster management, risk perception, sustainable development in China, and information 
management. In 2009, he was honored by Program for New Century Excellent Talents in University. He has published over 40 full review journal articles in Chinese and English since 2006, and conducted research or provided technical services to 6 different organizations in public and private sectors in China. Also, he also served as reviewers of NSFC proposals and over ten academic journals. 